\title{
Avaliação de Características Física, Química e Microbiológica da Água na Microbacia do Córrego Gumitá, Cuiabá-MT
}

\section{Physical Characteristics Assessment, Chemical and Microbiological Water in Watershed Córrego Gumitá, Cuiaba-MT}

\author{
Mayse Teixeira Onohara ${ }^{1}$ \\ Antonio Pereira de Figueiredo Netto ${ }^{2}$ \\ Ana Rafaela Nascimento ${ }^{3}$ \\ Wilson Ferreira da Silva Junior ${ }^{4}$ \\ Rafaelle Cristiane da Silva Cerqueira ${ }^{5}$ \\ Amanda Finger ${ }^{6}$ \\ Eduardo Beraldo de Morais ${ }^{7}$
}

${ }^{1234}$ Discentes do curso de Engenharia Sanitária e Ambienta-ESA. Departamento de Engenharia Sanitária e Ambienta- DESA. Universidade Federal de Mato Grosso- UFMT.

${ }^{5}$ Graduada em Engenharia Sanitária e Ambiental. DESA-UFMT

${ }^{67}$ Docentes do DESA/UFMT

Enviado, aceito e publicado em: Junho 2015

RESUMO : A qualidade da água vem sofrendo alterações de ordem ambiental, social e econômica. Existem variáveis que classificam tal recurso como de melhor ou pior qualidade, sendo a de pior consequência de diversos problemas ambientais, que podem ser atribuídos tanto à ação antrópica, como despejo de efluentes doméstico, lançamento de resíduos sólidos, ocupações indevidas, quanto às mudanças que vem ocorrendo naturalmente no Meio Ambiente, como alterações na temperatura da água devido as condições climáticas, que em sua grande maioria estão indiretamente relacionadas com essas ações. Deste modo torna-se imprescindível a avaliação das características físicas, químicas e microbiológicas da água. Desta forma o presente trabalho buscou avaliar a qualidade da água da microbacia do Córrego Gumitá para verificar o seu enquadramento na legislação vigente, bem como avaliar os possíveis impactos causados e suas respectivas causas. Os resultados obtidos, mostraram que as águas sofrem impactos resultantes do lançamento de efluentes domésticos não tratados bem como de resíduos sólidos despejados pela população urbana que reside em suas margens. Levou-se em consideração análises de características físicas, químicas e microbiológicas no período chuvoso, sendo estas comparadas com os valores obtidos no período de seca e ainda com os padrões estabelecidos pelas Resoluções $n^{\circ}$ 357/2005 e n ${ }^{\circ}$ 430/2011 do CONAMA. Encontraram-se em desacordo com a legislação vigente as variáveis físicas, cor e turbidez; as variáveis químicas pH, DBO e óleos e graxas e as variáveis microbiológicas, coliformes totais e termotolerantes.

Palavras-chave: Qualidade da água, Córregos Urbanos, Esgoto Doméstico.

ABSTRACT: Water quality has been changing environmental, social and economic order. There are variables that classify this resource as better or worse quality, and the worst consequence of various environmental issues, which can be attributed as much to human actionas dump domestic waste, discharge of solid waste, unauthorized occupations, as the changes that It has been occurring naturally in the environment, such as changes in water temperature due to climate conditions, which mostly are indirectly related to these actions. Therefore it is essential to evaluating the physical, chemical and microbiological characteristics water. Thus, the present study sought to evaluate the quality of the watershed water Gumitá Stream to check your frame in the current legislation and to assess the possible impacts caused and their causes. The results showed that its waters suffer Impacts of domestic effluent discharge untreated and solid waste dumped by the urban population living on its banks. It took into consideration analyzes of physical, chemical characteristics and microbiological characteristics the rainy season, which are compared with the values obtained during the dry season and still compared to the standards established by Resolutions No. 357/2005 and No. 430/2011 of CONAMA. They found themselves at odds with current legislation the physical, color and turbidity; chemical variables $\mathrm{pH}, \mathrm{BOD}$ and oils and greases and microbiological variables, total and fecal coliforms.

Keywords: Water Quality, Urban Streams, Sewage Domestic. 
Onohara M. T., Netto A. P. F., Nascimento A. R., Silva W. F. J., Cerqueira R. C. S., Finger A., Morais E. B. Avaliação de Características Física, Química e Microbiológica da Água na Microbacia do Córrego Gumitá, Cuiabá-MT. E\&S - Engineering and Science, (2015), 1:3.

\section{INTRODUÇÃO}

A água é o principal recurso natural essencial para todas as formas de vida, e assume um papel fundamental no desenvolvimento das populações: na alimentação, na higiene, na produção de energia, na agricultura, na indústria, dentre outras aplicações; além de possuir um grande valor econômico, ambiental e social.

A concentração populacional em áreas urbanas foi sendo intensificada a partir da segunda metade do século XX e se tornou um fenômeno mundial. No Brasil, a concepção higienista fez da canalização e retificação dos córregos urbanos juntamente com a execução das galerias de águas pluviais, a única solução aos problemas urbanos de alagamentos e inundações e teve como intuito transferir a jusante para o mais longe da população o volume gerado pelas águas das chuvas, sem a devida preocupação dos impactos causados ao ciclo hidrológico, seja pelo aumento dos picos das vazões, ou ainda, a diminuição da recarga das águas subterrâneas. (MENEZES FILHO \& AMARAL, 2014)

As mudanças na quantidade, na distribuição e na qualidade dos recursos hídricos ameaçam a sobrevivência humana e demais espécies do planeta. O crescimento populacional e o crescimento das atividades econômicas,no meio urbano e no meio rural podem ser citados como causas do consumo elevado e da deterioração desses recursos (BORGES, GALBIATTI, \& FERRAUDO, 2003).

A água contaminada por agentes físicos, químicos e biológicos tem sido associada a diversos problemas de saúde, sendo que a principal exigência pela Portaria do Ministério da Saúde $\mathrm{n}^{\mathbf{0}}$ 2.914/2011 é assegurar a qualidade e potabilidade da distribuição de água para a população (BRASIL, Portaria $n^{\circ} 2.914$, 2011). A portaria estabelece os procedimentos de controle e de vigilância da qualidade da água para consumo humano e seu padrão de potabilidade, sendo importante observar as desconformidades das variáveis, já que estas podem representar contaminação do corpo d'água por lançamentos de efluentes não tratados, que torna a água imprópria para o consumo humano. TUCCI, 2008, cita como impacto sobre as águas urbanas, a falta de tratamento de esgoto doméstico, que ocorre em grande parte das cidades, que são lançados nas redes de esgotamento pluvial, escoando assim diretamente para os rios e córregos.

A análise da qualidade da água fornece subsídios para avaliar os impactos causados pela ação do homem em um meio aquático, possibilitando, por sua vez, seu manejo de forma adequada e até mesmo sua remediação. Em decorrência disso, torna-se indispensável o conhecimento dos usos atuais, de um corpo d'água e a gestão de planejamento para identificar os fatores que afetam a qualidade da mesma (BRASIL, 2006).

Os padrões de qualidades de água no Brasil são regidos pelas Resoluções n³57/2005 do Conselho Nacional do Meio Ambiente (CONAMA), que dispõe sobre a classificação dos corpos d'água e as diretrizes ambientais para o seu enquadramento, estabelecendo as condições e padrões de lançamento de efluentes $n^{\circ} 430 / 2011$ que dispões sobre as condições e padrões de lançamento que altera parcialmente Resolução n³57/2005. A região hidrográfica do Médio Cuiabá é drenada pelos rios Cuiabá e Coxipó, além de possuir vários ribeirões e córregos. $\mathrm{O}$ crescimento acelerado da Baixada Cuiabana ocorreu por volta da década de 80, caracterizada pelas ocupações irregulares em áreas de preservações ambientais (APPs) ao longo das margens dos rios e córregos, sem atender o devido planejamento e cumprimento das legislações urbanas, descaracterizando as paisagens naturais (MENEZES FILHO \& AMARAL, 2014). 
Onohara,M.T, et al (2015).Avaliação de Características Física, Química e Microbiológica da Água na Microbacia do Córrego Gumitá, Cuiabá-MT

O córrego Gumitá é um dos principais córregos que cortam a cidade de Cuiabá, está em acelerado processo de degradação ambiental, pela utilização de forma inadequada por parte população, ocasionando sérios desequilíbrios, como presença de contaminação de origem doméstica, resultando na perda de qualidade de suas águas e o assoreamento das margens, chegando a se tornar apenas um fio d'água em alguns pontos (CARVALHO M. , 2011).

A poluição hídrica ocorre muitas vezes devido à falta de programas governamentais e socioambientais, e isso contribui com a falta de controle habitacional às margens de córregos urbanos e outras áreas que deveriam ser preservadas (SILVA \& JARDIM, 2007).

Em Cuiabá existem mais de 20 córregos de drenagem que recebem o esgoto doméstico e industrial e o córrego Gumitá é um dos córregos inserido no perímetro urbano da cidade, tem sua nascente localizada na área urbana, nas proximidades do Hospital do Câncer e ao longo do seu percurso recebe efluente de outros córregos até chegar ao encontro com o córrego Moinho, no bairro Planalto e está sofrendo interferência devida a ação antrópica (CASTRO JÚNIOR \& OLIVEIRA, 2011). A ocupação das margens do córrego Gumitá teve início por volta da década de 1980 com a criação dos núcleos habitacionais CPA I, II, III e Morada do Ouro e é possível observar ao longo do córrego Gumitá diversos problemas provocados por esta ocupação sem planejamento (IPDU, 2007).

Assim, o presente trabalho teve como finalidade avaliar a qualidade físicoquímica e microbiológica das águas do Córrego Gumitá, e a partir dos resultados obtidos com ensaios físico, químico e microbiológico no período chuvoso, confrontando-os com ensaios previamente realizados em períodos de seca bem como com as legislações vigentes, tais como
Resoluções $n^{\circ} 357 / 2005$ e $n^{\circ} 430 / 2011$ do CONAMA, e notas técnicas do Conselho Estadual de Recursos Hídricos do Estado de Mato Grosso, que propõe uma adequação no enquadramento dos córregos urbanos a partir de análises realizadas.

\section{MATERIAL E MÉTODOS}

A área de estudo escolhida foi a microbacia do Córrego Gumitá, que está localizada na cidade de Cuiabá-MT. Possui extensão aproximada de $6 \mathrm{~km}$ com área de $27.368 \mathrm{~m}^{2}$, localizada nas coordenadas geográficas $15^{\circ} 35^{\prime} \mathrm{S}$ e $56^{\circ} 06^{\prime} \mathrm{W}$, conforme Figura 1 e com altitude média de $165 \mathrm{~m}$ (CARVALHO M. , 2011).

A micro bacia foi dividida em três pontos de coleta para amostragens, sendo identificados como P0, P1, P2 onde P0 está localizado na nascente, P1 aproximadamente a $3 \mathrm{~km}$ da nascente e P2 no encontro com o córrego Moinho. $\mathrm{Na}$ escolha dos pontos ao longo do córrego considerou-se a proximidade deste a nascente, fatores como a facilidade de acesso e o ponto final nas proximidades do encontro do Córrego Gumitá com do Moinho, de modo à melhor caracterizar a qualidade das águas. A delimitação dos pontos de coleta do Córrego Gumitá é demonstrada na Figura 2.

Foram realizadas coletas no período de seca (nos meses de junho, julho e agosto de 2013) e no período de chuva (no mês de dezembro de 2014) a fim de compararemse os resultados obtidos nestes diferentes períodos principalmente relacionados às possíveis contaminações de efluentes domésticos que possam estar sendo ali despejados.

As coletas foram realizadas em conformidade com a NBR 9898 de 1987, que dispõe da preservação e técnicas de amostragem de efluentes líquidos e corpos receptores (ABNT, 1987). 
Onohara M. T., Netto A. P. F., Nascimento A. R., Silva W. F. J., Cerqueira R. C. S., Finger A., Morais E. B. Avaliação de Características Física, Química e Microbiológica da Água na Microbacia do Córrego Gumitá, Cuiabá-MT. E\&S - Engineering and Science, (2015), 1:3.

Figura 1. Mapa da localização do córrego Gumitá, Cuiabá-MT.

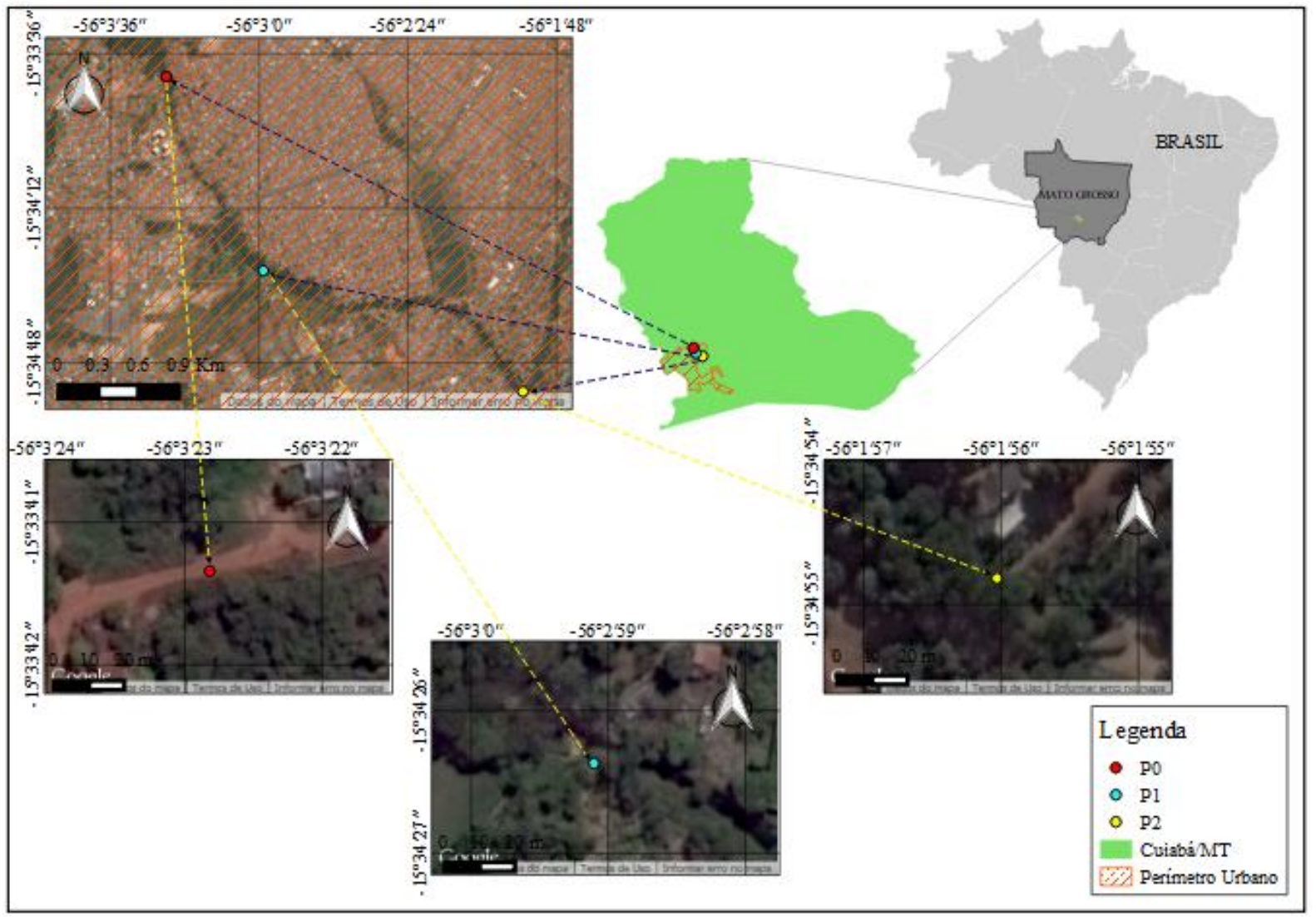

Figura 2. Pontos de Amostragem do córrego Gumitá.

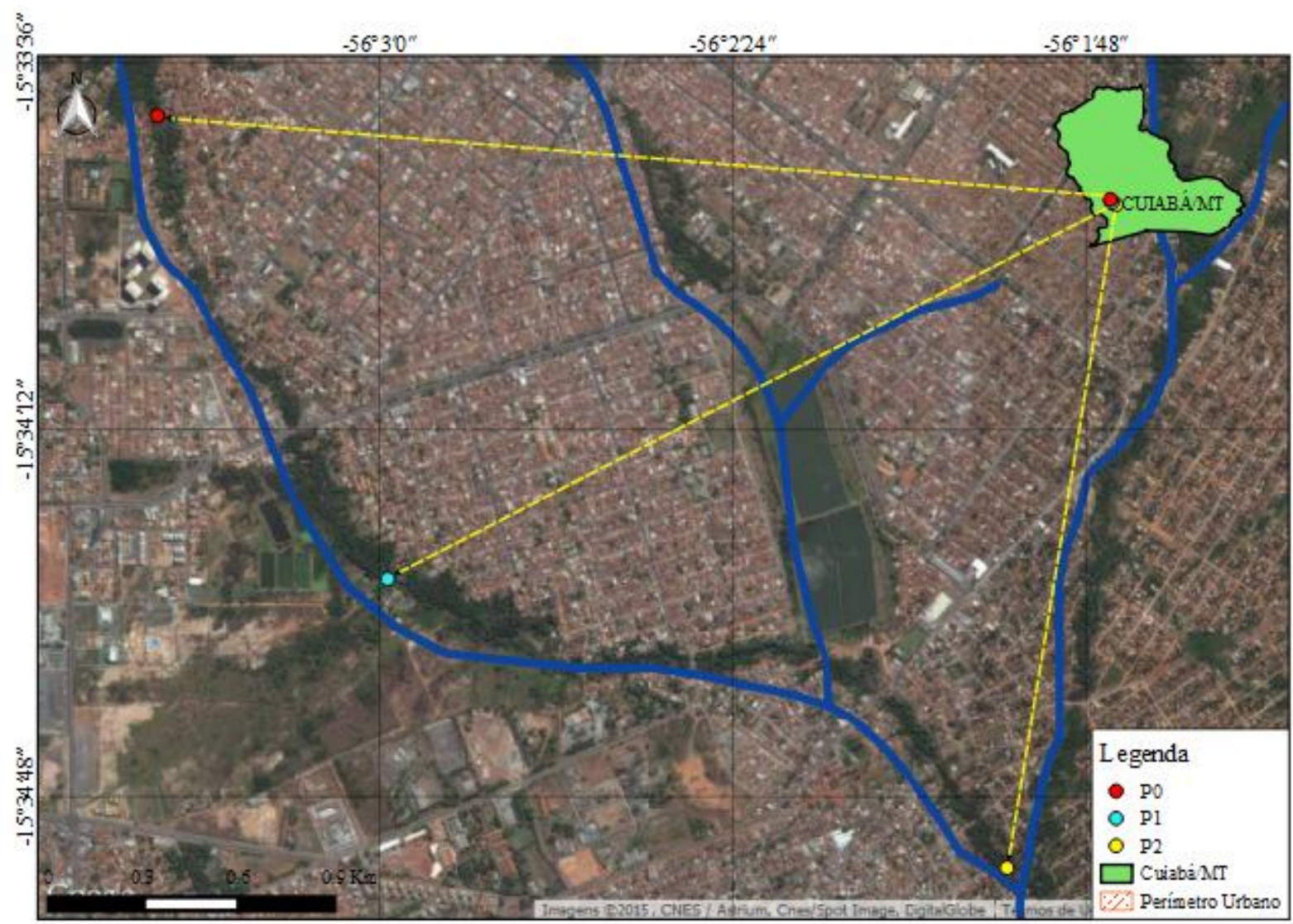


Onohara,M.T, et al (2015).Avaliação de Características Física, Química e Microbiológica da Água na Microbacia do Córrego Gumitá, Cuiabá-MT

As análises realizadas contemplaram parâmetros físicas tais como temperatura, turbidez, cor e condutividade elétrica, químicos como $\mathrm{pH}$, alcalinidade total, cloretos, DQO, DBO, saturação de oxigênio, óleos e graxas e sólidos e microbiológicos em que foram determinados coliformes totais e coliformes termotolerantes.

A partir dos resultados obtidos efetuou-se a comparação dos mesmos com

Tabela 1. Variáveis Físicas analisadas. os valores padrões legais das Resoluções $n^{\circ} 357 / 2005$ e $n^{\circ} 430 / 2011$ do CONAMA estabelecidos para corpos d'água Classe 2, bem como uma comparação dos resultados nos diferentes períodos de seca e chuvoso. Nas Tabelas 1, 2 e 3 estão apresentados os parâmetros físicos, químicos e microbiológicos avaliados, respectivamente, assim como a metodologia de determinação.

\begin{tabular}{ccc}
\hline Variável & Unidades & Metodologia Analítica / Equipamento empregado \\
\hline Condutividade & $\mathrm{mS} / \mathrm{cm}$ & Condutivímetro - RS 232 \\
Cor & Units & Espectrofotômetro - Hach DR 2700 \\
Sólidos Sedimentáveis & $\mathrm{mg} / \mathrm{L}$ & Gravimétrico \\
Temperatura & ${ }^{\circ} \mathrm{C}$ & Termômetro - Campo e laboratório \\
Turbidez & $\mathrm{UNT}$ & Turbidímetro - RS 232 \\
\hline
\end{tabular}

Tabela 2. Variáveis Químicas analisadas.

\begin{tabular}{ccc}
\hline Variável & Unidades & Metodologia Analítica / Equipamento empregado \\
\hline $\mathrm{pH}$ & - & pHmetro de bancada \\
Alcalinidade & $\mathrm{mg} / \mathrm{L}$ & Titulação Potenciométrica / Bureta \\
Cloretos & $\mathrm{mg} / \mathrm{L}$ & Titulação Argentométrica / Bureta \\
$\mathrm{DQO}$ & $\mathrm{mg} / \mathrm{L}$ & Digestor / Espectrofotômetro \\
$\mathrm{DBO}$ & $\mathrm{mg} / \mathrm{L}$ & Winkler \\
Oxigênio Dissolvido & $\mathrm{mg} \mathrm{O} / \mathrm{L}$ & Eletrométrico / Oxímetro \\
Saturação de Oxigênio & $\mathrm{mg} \mathrm{O} / \mathrm{L}$ & Eletrométrico / Oxímetro \\
Óleos e Graxas & $\mathrm{mg} / \mathrm{L}$ & Gravimétrico \\
\hline
\end{tabular}

Tabela 3. Variáveis Microbiológicas analisadas.

\begin{tabular}{ccc}
\hline Variável & Unidades & Metodologia Analítica / Equipamento empregado \\
\hline Coliformes Totais & NMP / 100mL & Tubos Múltiplos \\
Coliformes Termotolerantes & NMP / 100mL & Tubos Múltiplos \\
\hline
\end{tabular}

\section{RESULTADOS E DISCUSSÃO}

Diversos estudos acerca da qualidade da água do córrego Gumitá estão sendo realizados, conforme dados obtidos abaixo, com o objetivo de monitorar e avaliar as condições atuais do recurso hídrico em questão. A partir dos dados obtidos, pode-se inferir que o ambiente estudado vem sofrendo alterações devido à despejos de efluentes domésticos, ocupação irregular nas suas margens, que fazem com que a qualidade da água sofra alterações significativas, tornando-a assim imprópria para o consumo humano.

\section{Variáveis Físicas}

A Tabela 4 apresenta os resultados obtidos das variáveis físicas nos períodos de seca e de chuva, bem como a legislação com a qual foram analisados se atendem aos padrões mínimos estabelecidos. 
Onohara,M.T, et al (2015).Avaliação de Características Física, Química e Microbiológica da Água na Microbacia do Córrego Gumitá, Cuiabá-MT

A condutividade elétrica de uma solução é a capacidade desta em conduzir corrente elétrica através da concentração dos íons presentes. A avaliação deste parâmetro permite indicar a presença de sais, minerais ácidos e contaminantes lançados nos sistemas aquáticos (ESTEVES, 2011)

A condutividade apresentou altos valores, acima de $100 \mathrm{mS} / \mathrm{cm}$ em todos os pontos coletados nos períodos de chuva e seca, não atendendo a resolução CONAMA $n^{\circ} 357 / 05$ que apresenta a condutividade máxima em $100 \mathrm{mS} / \mathrm{cm}$. Essa elevação da condutividade pode estar sendo causada pela presença de substâncias poluentes procedentes dos esgotos lançados direto no córrego. A importância de avaliar a condutividade em um manancial relaciona-se com a possibilidade de se detectar pontos de poluição, pois, em ambientes naturais, a condutividade mostra valores extremamente baixos (VTZ, 1997apud NEIVA, 2004).

Conforme PINTO et al (2010) a profundidade e temperatura são influenciadas pelo regime climático normal, e os corpos d'água naturais sofrem os impactos dessa influência, apresentando variações sazonais e diurnas. A temperatura superficial pode ser influenciada por fatores como altitude, latitude, período do dia, estação do ano, taxa de fluxo e profundidade

Tabela 4. Resultados obtidos das variáveis físicas.

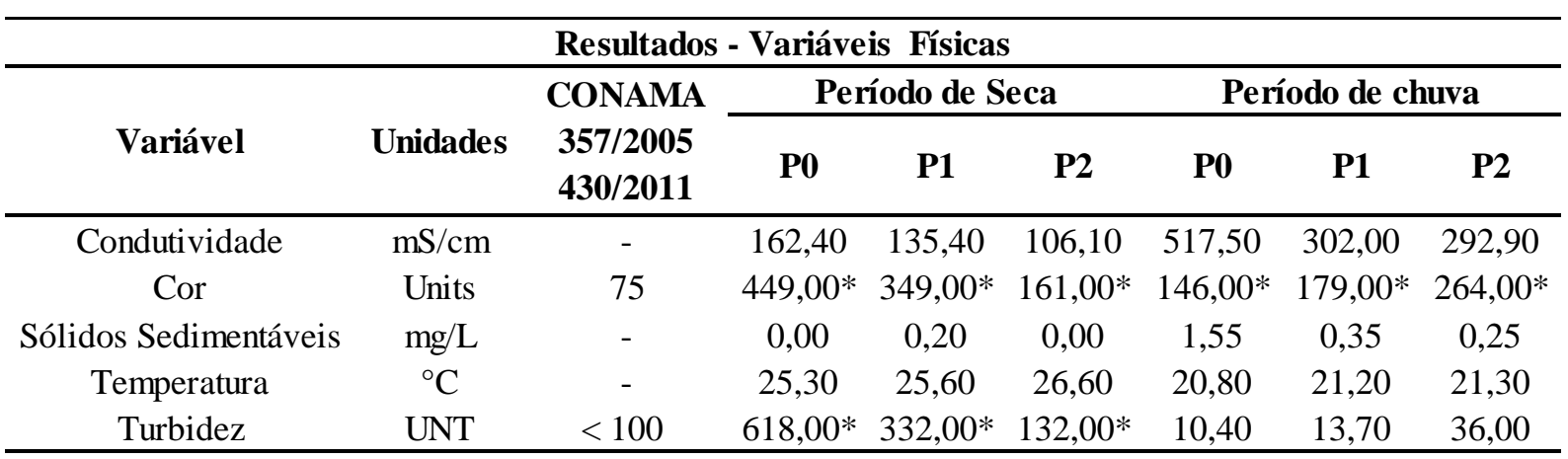

*Dados em desconformidade com o padrão estabelecido na Resolução CONAMA nº 357/2005 e nº 430/2011

$\mathrm{Na}$ análise dos dados obtidos para a condutividade elétrica, observa-se que durante o período de seca, os valores são menores que no período de chuva. Apesar deste resultado significar que no período de chuva o córrego está mais poluído, deve-se levar em conta o fato de terem sido realizadas as coletas em períodos distintos, podendo assim ser um indicativo de elevação no teor de poluição do córrego. Tem-se que quanto mais poluída estiver a água, maior será a condutividade em função do aumento do conteúdo mineral (MANARA \& CLEMENTE, 2011). ZILLMER et al , 2007, mencionam que os íons responsáveis pelos valores de condutividade são chamados de micronutrientes tais como cálcio, magnésio, potássio, sódio, carbonato, sulfato e cloreto.
A cor indica a presença de substâncias dissolvidas ou finamente divididas que transmitem coloração específica à água. Em todos os pontos estão acima do permitido pelas Resoluções $n^{\circ} 357 / 2005$ do CONAMA que estabelece ordem de $75 \mathrm{uH}$. Os maiores valores encontrados, tem relação com aumento da turbidez nesses mesmos pontos, como por exemplo, nos pontos $\mathrm{P} 0$ no período de seca e P2 no período de chuva. Responsável pela coloração das águas (VON SPERLING, 1995). Parâmetro de aspecto estético de aceitação ou rejeição do produto.

As Resoluções $n^{\circ} 357 / 2005$ e $n^{\circ}$ 430/2011 do CONAMA estabelecem valores limites de sólidos totais na água, porém o presente estudo avaliou somente os sólidos sedimentáveis. A presença de 
Onohara,M.T, et al (2015).Avaliação de Características Física, Química e Microbiológica da Água na Microbacia do Córrego Gumitá, Cuiabá-MT

sólidos indica a possibilidade de turvação da água com o impedimento de penetração da luz. Os valores obtidos mostram a presença de sólidos sedimentáveis apenas no período chuvoso, possivelmente causado pelas chuvas decorrentes do período que revolvem os sedimentos e os desprendem do leito do Córrego, elevando os índices obtidos.

A temperatura é um parâmetro físico (uma função de estado) descritivo de um sistema que vulgarmente se associa as noções de frio e calor, bem como as transferências de energia térmica, mas que se poderia definir, mas exatamente sob ponto de vista microscópico, como medida da energia cinética associada ao movimento (vibração) aleatório das partículas que compõem um dado sistema físico (VON SPERLING, 1995). A temperatura é um parâmetro de grande importância, dado que tem influência na velocidade das reações químicas, na solubilidade dos gases, na taxa de crescimento dos microrganismos, entre outras (SOUSA, 2001). No período de chuva observou-se temperaturas mais baixas da água devido às precipitações ocorridas, em que normalmente a temperatura da água da chuva é mais baixa, e ao misturar-se com a água do córrego, consequentemente diminui a sua temperatura. As Resoluções $n^{\circ}$ 357/2005 do CONAMA não estabelecem valores de temperatura para classificação de corpo hídrico.

A turbidez é uma propriedade física que se deve presença de partículas em suspensão (material insolúvel) presentes na água e que impedem ou dificultam a passagem de luz (SOUSA, 2001). O resultado das análises indicou que os valores de turbidez estavam fora do padrão da resolução do CONAMA 357/2005 apenas no período de seca, fato que se difere do estudo realizado na microbacia do Córrego Rico, por ZANINI, et al, 2010, que cita o fato de em períodos chuvosos, a quantidade de material suspenso aumentar a turbidez

\section{Variáveis Químicas}

Segundo CARVALHO et al (2000), variáveis como $\mathrm{pH}$, oxigênio dissolvido, entre outras, pode auxiliar na caracterização da qualidade do corpo hídrico e sofrem influência das estações do ano. Das variáveis químicas analisadas, têm-se dados que não atendem às condições ideais estabelecidas pelas Resoluções 357/2005 e 430/2011 do CONAMA, tais como pH, DBO, oxigênio dissolvido e óleos e graxas, conforme demonstrado na Tabela 5, que tem como principal causa o despejo de efluentes domésticos, justificado pelas ocupações em seu entorno, pelas precárias condições de saneamento básico dos locais estudados.

As condições ideais de $\mathrm{pH}$ para vida aquática segundo as Resoluções $\mathrm{n}^{\circ}$ 357/2005 e no 430/2011 do CONAMA está dentro da faixa de 6,0 a 9,0. Observa-se em dois pontos no período de seca, que esta variável está em desconformidade com o padrão estabelecido, com valores entre 9,0 a 9, 3, que pode indicar presença de despejos industriais ou até mesmo de esgoto doméstico. PEREIRA (2004), afirma que as variações do $\mathrm{pH}$ nos corpos d'água estão relacionadas também com aoxidação da matéria orgânica, confirmando a contaminação por despejos indevidos de efluentes domésticos, ricos em matéria orgânica.

As Resoluções $n^{\circ} 357 / 2005$ e $n^{\circ}$ 430/2011 do CONAMA, não estabelecem padrões mínimos de alcalinidade, porém os valores elevados de alcalinidade além de apresentar gosto desagradável, podem causar alguns danos à saúde devidos o seu efeito laxativo (Von SPERLING, 2005)e pode ser indicativo de despejo de efluente doméstico, já que a decomposição da matéria orgânica aumenta a geração de gás carbônico, elevando assim a alcalinidade do meio, que consequentemente influencia no aumento do $\mathrm{pH}$. A alcalinidade segue o padrão de diminuição em seus índices durante o período de chuva, que é causado pela diluição da água por consequência das chuvas do período analisado, encontrando- 
Onohara,M.T, et al (2015).Avaliação de Características Física, Química e Microbiológica da Água na Microbacia do Córrego Gumitá, Cuiabá-MT

se o valor mais elevado no ponto 0 no período de seca, de $284 \mathrm{mg} / \mathrm{L}$ de $\mathrm{CaCO} 3$, e

no período de chuva o maior.

Tabela 5. Resultados obtidos das variáveis Químicas.

\begin{tabular}{|c|c|c|c|c|c|c|c|c|}
\hline \multirow[b]{3}{*}{ Variável } & \multirow[b]{3}{*}{ Unidades } & \multicolumn{7}{|c|}{ Resultados - Variáveis Químicas } \\
\hline & & \multirow{2}{*}{$\begin{array}{c}\text { CONAMA } \\
357 / 2005 \\
430 / 2011\end{array}$} & \multicolumn{3}{|c|}{ Período de Seca } & \multicolumn{3}{|c|}{ Período de chuva } \\
\hline & & & P0 & P1 & $\mathbf{P 2}$ & P0 & P1 & $\mathbf{P 2}$ \\
\hline $\mathrm{pH}$ & - & $6,0-9,0$ & $9,26^{*}$ & $9,01 *$ & 8,96 & 8,20 & 7,80 & 7,40 \\
\hline Alcalinidade & $\mathrm{mg} / \mathrm{L}$ & - & 284,18 & 159,85 & 126,87 & 14,61 & 16,78 & 20,57 \\
\hline Cloretos & $\mathrm{mg} / \mathrm{L}$ & 250 & 131,75 & 81,78 & 86,32 & 7,98 & 9,90 & 10,54 \\
\hline DQO & $\mathrm{mg} / \mathrm{L}$ & - & 130,67 & 85,67 & 105,00 & 48,00 & 51,70 & 53,00 \\
\hline DBO & $\mathrm{mg} / \mathrm{L}$ & $<5$ & $87,36^{*}$ & $39,56^{*}$ & $37,33^{*}$ & 4,13 & $7,18^{*}$ & $8,32 *$ \\
\hline DQO/DBO & $\mathrm{mg} / \mathrm{L}$ & - & 1,5 & 2,17 & 2,81 & 11,62 & 7,2 & 6,37 \\
\hline Oxigênio Dissolvido & $\mathrm{mg} \mathrm{O} 2 / \mathrm{L}$ & $>5$ & 6,29 & $4,81^{*}$ & $3,65^{*}$ & 7,08 & 7,35 & 6,57 \\
\hline Saturação de Oxigênio & $\%$ & - & 70,70 & 54,50 & 41,50 & 88,80 & 92,60 & 84,10 \\
\hline Óleos e Graxas & $\mathrm{mg} / \mathrm{L}$ & ausentes & 0,00 & 0,00 & 0,00 & $0,44 *$ & $0,37 *$ & $0,42 *$ \\
\hline
\end{tabular}

*Dados em desconformidade com o padrão estabelecido na Resolução CONAMA nº 357/2005 e n 430/2011

Para a variável cloretos, as Resoluções $n^{\circ} 357 / 2005$ e $n^{\circ} 430 / 2011$ do CONAMA, estabelece valor máximo de $250 \mathrm{mg} \mathrm{Cl}^{-} \mathrm{L}^{-1}$, e os resultados obtidos mostram que em todos os pontos avaliados em ambos os períodos atende ao padrão estabelecido. Os íons cloretos podem indicar contaminação para fontes que recebam de forma inadequada esgotos domésticos, e assim elevadas concentrações podem indicar esse despejo, mesmo que dentro dos valores padrões estabelecidos em resolução, é um importante fator indicador (LIMA, FRANÇA, \& LOIOLA, 2014).

A DQO corresponde a quantidade de oxigênio requerida para estabilizar quimicamente a matéria-orgânica carbonácea utilizando fortes agentes oxidantes, sendo um dos parâmetros de maior importância na caracterização do grau de poluição de um corpo d'água por matéria-orgânica (Von SPERLING, 2005). Pode ver claramente um aumento significativo da DQO ao longo dos pontos.As Resoluções $n^{\circ} 357 / 2005$ e $n^{\circ}$ 430/2011 do CONAMA não define padrão de limite para este parâmetro. Foram encontradas diferenças nos valores obtidos nos períodos seca e chuvoso, em que no primeiro são observado valores mais elevados, que indicam maior quantidade de matéria orgânica na água.

Para a DBO as Resoluções do CONAMA $n^{\circ} 357 / 2005$ e $n^{\circ} 430 / 2011$ limitam para corpo hídrico Classe 2, valor máximo de $5,0 \mathrm{mg} \mathrm{L}^{-1}$. Essa demanda é referida convencionalmente a um período de cinco dias, já que a estabilização completa da matéria orgânica exige um tempo maior, e a uma temperatura de 20 ${ }^{\circ} \mathrm{C}$, por isso a denominação $\mathrm{DBO}_{5}{ }^{20}$.

Os valores encontrados para o Córrego Gumitá estão bem acima da $\mathrm{DBO}_{5}{ }^{20}$ permitida na maioria dos pontos analisados em ambos os períodos, exceto no ponto P0 no período de chuva. Em ambientes naturais não poluídos, são encontrados valores de DBO baixo (1 $\mathrm{mg} / \mathrm{L}$ a $10 \mathrm{mg} / \mathrm{L}$ ), e podem atingir valores mais elevados em corpos d'água sujeitos à poluição orgânica. Normalmente decorrente do recebimento de esgotos domésticos (BRASIL, 2006).

REPULA \& QUINÁIA (2009) explicam que quando a razão de $\mathrm{DBO}_{5}{ }^{20} \mathrm{e}$ DQO é acima de 5, valor considerável para efluentes, a fração da matéria não biodegradável é muito maior do que da matéria biodegradável. Como se trata de 
Onohara,M.T, et al (2015).Avaliação de Características Física, Química e Microbiológica da Água na Microbacia do Córrego Gumitá, Cuiabá-MT

um córrego urbano, com lançamentos de esgoto doméstico e materiais inorgânicos direto no leito em vários pontos, acarreta um decaimento de oxigênio no corpo hídrico gerando uma desoxigenação no meio (JORDÃO, 2011).

Os dados obtidos permitem analisar que as relações DQO/DBO obtidas durante o período de seca apresentam menor relação que no período de chuva e ainda segundo REPULA \& QUINÁIA (2009), quanto menor essa relação, mais biodegradável é o efluente lançado, neste caso, o corpo d'água possui maior capacidade de biodegradação no período de seca do que no período de chuva.

Conforme as Resoluções $\mathrm{n}^{\circ}$ 357/2005 e $\mathrm{n}^{\circ} 430 / 2011$ do CONAMA, a quantidade de oxigênio dissolvido em qualquer amostra de um corpo hídrico Classe 2, não deverá ser inferior a $5 \mathrm{mg}$. $\mathrm{L}^{-}$ 1 . Dois dos resultados obtidos no período de seca nos pontos P1 e P2 estão em desconformidade com os padrões estabelecidos, o que não é observado no período chuvoso. BASSO \& PIZZATO (2011) explicam que baixas concentrações de oxigênio, ou seja, valores inferiores a 5 mg. $\quad \mathrm{L}^{-1}$ podem indicar processos de consumo de oxigênio através de efluentes de esgotos domésticos, podendo conduzir a morte de peixes mais exigentes em relação aos níveis de oxigênio na água.

As Resoluções $n^{\circ} 357 / 2005$ e $n^{\circ}$ 430/2011 do CONAMA estabelecem ausência de óleos e graxas. Os óleos e graxas em seu processo de decomposição reduzem o oxigênio dissolvido elevando a $\mathrm{DBO}_{5}{ }^{20}$ e a DQO, causando alteração no ecossistema aquático (CESTESB, 2009)Desta forma, ao observar a presença destes em todos os pontos do período de chuva, estão em desacordo com os padrões estabelecidos, pode-se inferir que estes podem estar causando tais alterações e causando desequilíbrio no sistema aquático de modo geral.

\section{Variáveis Microbiológicas}

A qualidade da água tem como um dos principais indicadores biológicos de qualidade um grupo de bactérias aeróbias ou anaeróbias capazes de fermentar a lactose de 24 a 48 horas a temperatura de 35 a $37{ }^{\circ} \mathrm{C}$, conhecidas como coliformes totais, composto pela Escherichia, Citrobacter, Klebsiella e Enterobacter. Alguns destes esses organismos são patógenos e outros só habitam o trato gastrintestinal, podendo ser encontrados em pastagens, solos, plantas submersas e mesmo em outros lugares do organismo (LIBÂNIO, 2005).

O grupo dos "coliformes fecais" ou termotolerantes toleraram e se reproduzem em temperaturas acima de $40{ }^{\circ} \mathrm{C}$ e em menos de 24 horas e é associado às fezes de animais de sangue quente. A determinação da concentração dos coliformes (totais e termotolerantes) é importante indicador da existência de bactérias patogênicas, que por sua vez podem ser responsáveis pela transmissão de doenças de veiculação hídrica, como febre tifóide, disenteria bacilar e cólera (CESTESB, 2009).

Segundo a Resoluções n ${ }^{\circ} 375 / 2005$

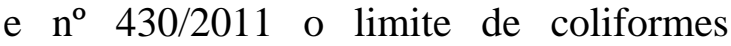
termotolerantes não pode ser superior a $1000 \mathrm{NMP} / 100 \mathrm{ml}$ em $80 \%$ ou mais de 6 amostras de coletas durante um ano para Classe 2.

Em todos os pontos analisados durante ambos os períodos, foram observados valores em desconformidade com os padrões estabelecidos, conforme pode ser visto na Tabela 6 . 
Onohara,M.T, et al (2015).Avaliação de Características Física, Química e Microbiológica da Água na Microbacia do Córrego Gumitá, Cuiabá-MT

Tabela 6. Resultados obtidos das variáveis Microbiológicas

\begin{tabular}{|c|c|c|c|c|c|c|c|c|}
\hline \multirow[b]{3}{*}{ Variável } & \multicolumn{5}{|c|}{ Resultados - Variáveis Microbiológicas } & & & \\
\hline & \multirow[b]{2}{*}{ Unidades } & \multirow{2}{*}{$\begin{array}{c}\text { CONAMA } \\
357 / 2005 \\
430 / 2011\end{array}$} & \multicolumn{3}{|c|}{ Período de Seca } & \multicolumn{3}{|c|}{ Período de chuva } \\
\hline & & & P0 & P1 & $\mathbf{P 2}$ & P0 & P1 & $\mathbf{P 2}$ \\
\hline Coliformes Totais & NMP / 100mL & 1000 & $1600^{*}$ & $1600 *$ & $1600 *$ & $1600 *$ & $1600^{*}$ & $1600 *$ \\
\hline Coliformes Termotolerantes & NMP / 100mL & 1000 & $1600 *$ & $1600^{*}$ & $1600 *$ & $1600 *$ & $1600 *$ & $1600 *$ \\
\hline
\end{tabular}

*Dados em desconformidade com o padrão estabelecido na Resolução CONAMA nº 357/2005 e n 430/2011

\section{CONSIDERAÇÕES FINAIS}

A Resolução CONAMA $n^{\circ}$ 357/2005 em seu Artigo 42 determina que enquanto não aprovados os respectivos enquadramentos, as águas doces são consideradas Classe 2, condição em que se aplica aos trechos do córrego Gumitá. Porém, verifica-se a partir de análises físicas, químicas e microbiológicas, que o mesmo apresentou resultados em desacordo com os padrões estabelecidos em legislação vigente para águas doce Classe 2.

Os resultados que apresentaram não conformidade com padrões físicos foram cor e turbidez, com os padrões químicos $\mathrm{pH}, \mathrm{DBO}, \mathrm{OD}$ e óleos e graxas, e coliformes totais e termotolerantes das variáveis microbiológicas. Possivelmente isso ocorre devido ao Córrego estar localizado em perímetro urbano, sem o devido cumprimento da área de preservação permanente com limite de 15 metros de cada margem estabelecida pela Resolução CONAMA n ${ }^{\circ}$ 303/2002, ocasionando a utilização desse corpo d'água como corpo receptor de efluentes domésticos e resíduos sólidos sem o devido tratamento (BRASIL, Resolução $n^{\circ}$ 303,2002 ).

\section{AGRADECIMENTOS}

Ao Laboratório de Análises FísicoQuímica de Água e Resíduos (LAFQAR) da Universidade Federal de Mato Grosso, especialmente aos técnicos Luanna Mênithen Suza Silva Santos e Daniel Filho e à Kamila Almeida Oliveira pela colaboração nas coletas e identificação dos pontos.

\section{REFERÊNCIAS BIBLIOGRÁFICAS}

ABNT. (1987). NBR 9898. Preservação e Técnicas de Amostragem de Efluentes Líquidos e Corpos Receptores. Rio de Janeiro, RJ: Associação Brasileira de Normas Técnicas.

BASSO, L., \& PIZZATO, F. A. (2011). Qualidade da água da bacia hidrógrafica do arroio do Salso, . Porto Alegre, RS: XIV Simpósio Brasileiro de Geografia Física Aplicada.

BORGES, M., GALBIATTI, J., \& FERRAUDO, A. (2003). Qualidade Hídrica e Eficiência de Interceptores de Esgostos em Cursos d'Água Urbanos da Bacia Hidrográfica do Córrego Jaboticabal. Revista Brasileira de Recursos Hídricos, 161-171.

BRASIL. (2002). Resolução no 303 . Brasília , DF: CONAMA, Ministério do Meio Ambiente.

BRASIL. (17 de Março de 2005). Resolução no 357. Brasília, DF: CONAMA, Ministério do Meio Ambiente.

BRASIL. (2006). Vigilância e Controle da qualidade da água para consumo humano . 212. Brasília: Ministério da Saúde, Secretaria de Vigilância em Saúde. 
Onohara,M.T, et al (2015).Avaliação de Características Física, Química e Microbiológica da Água na Microbacia do Córrego Gumitá, Cuiabá-MT

BRASIL. (13 de Maio de 2011). Resolução no 430. Brasília, DF: CONAMA, Ministério do Meio Ambiente.

BRASIL. (12 de Dezembro de 2011). Portaria no 2.914. Brasília, DF: Ministério da Saúde.

CARVALHO, A., SCHLITTLER, F., \& TORNISIELO, V. (2000). Relações da atividade agropecuária com parâmetros físicos quimicos da água. Química Nova.

CARVALHO, M. (2011). Microbacias Urbanas, urbanização e áreas de preservação permanente: o caso do córrego Gumitá, Cuiabá-MT. Trabalho de Conclusão de Curso. Cuiabá: Instituto Federal de Mato Grosso .

CASTRO JÚNIOR, E., \& OLIVEIRA, M. R. (2011). Identificação e Discussão sobre os problemas do córrego Gumitá na Cidade de Cuiabá - Mato Grosso. Londrina, PR: II CONGRESSO BRASILEIRO DE GESTÃO AMBIENTAL.

CESTESB. (2009). Qualidade das águas interiores no estado de São Paulo, significado ambiental e sanitário das variáveis de qualidade das águas e dos sedimentos e metodologias analíticas e de amostragem. São Paulo: Companhia de Tecnologia de Saneamento Ambiental.

ESTEVES, F. (2011). Fundamentos de Limnologia. Rio de Janeiro: Interciência.

FUNASA. (2006). Manual Prático de análise de água. Brasília: Fundação Nacional da Saúde.

HELLER, L., COLOSIMO, A. E., \& ANTUNES, C. M. (2003). Environmental sanitation conditions and health impact: a casecontrol study. Rev. Soc. Bras. Med. Trop, 45-50.

IPDU. (2007). Perfil Socioeconômico de Cuiabá. 3, 486. Cuiabá: Instituto de
Planejamento e Desenvolvimento Urbano.

JORDÃO, E. P. (2011). Tratamento de Esgoto Doméstico. Rio de Janeiro: ABES.

LIBÂNIO, M. (2005). Fundamentos de Qualidade e tratamento de água. Átomo.

LIMA, J. O., FRANÇA, A. M., \& LOIOLA, H. G. (2014). Implicações Hidroquímicas da condutividade elétrica e do íon cloreto na qualidade das águas subterrâneas do semiárido cearense. Revista Virtual de Química, 279-292.

MANARA, A., \& CLEMENTE, A. (2011). Qualidade d'água de microbacia urbana, córrego Lavapés na cidade de Mogi Mirim - SP. Scientia Plena, 7(8).

MENEZES FILHO, F., \& AMARAL, D. B. (2014). Histórico da expansão urbana e ocorrência de inundações na cidade de Cuiabá-MT. Soc. \& Nat., 159-170.

NEIVA, I. S. (2004). O processo de urbanização e a bacia hidrográfica do Córrego Paragem . Monografia . Dourados, MS: UEMS.

PEREIRA, R. S. (2004). Poluição hídrica: causas e consequencias. Revista Eletrônica de Recursos Hídricos, 20-36.

PINTO, A. L., OLIVEIRA, G. H., \& PEREIRA, G. H. (2010). Avaliação da eficiência do oxigênio dissolvido como principal indicador da qualidade das águas superficiais da bacia do córrego Bom Jardim. GEOMAE.

REPULA, C. M., \& QUINÁIA, S. P. (2009). Avaliação da qualidade da água do córrego Viaduto, utilizando anáise de componentes principais. Ambiência, 433-442.

SEMA-MT. (2011). Relatório de determinação dos usos preponderantes mais restritivos de trecho do Córrego 
Onohara,M.T, et al (2015).Avaliação de Características Física, Química e Microbiológica da Água na Microbacia do Córrego Gumitá, Cuiabá-MT

Gumitá e Córrego do Caju. Cuiabá: SEMA.

SILVA, G. S., \& JARDIM, W. F. (2007). Aplicação do método da carga máxima total diária (CMTD) para a amônia no Rio Atibaia, região de Campinas/Paulínia SP. Engenharia Sanitária e Ambiental.

SOARES, S., BERNARDES, R., \& NETTO, O. (2002). Relações entre saneamento, saúde pública e meio ambiente: elementos para formulação de um modelo de planejamento em saneamento. Cad. Saúde Pública, 18(6), 1713-1724.

SOUSA, E. (2001). Qualidade da Água dos Recursos Hídricos e Ambientais. Tese de Doutorado. UNIP.

TUCCI, C. E. (2008). Águas Urbanas. Estudos Avançados, pp. 97-112.
VON SPERLING, M. (1995). Princípios do Tratamento Biológico de Águas Residuárias - Introdução à qualidade das águas e ao tratamento de Esgotos. Minas Gerais: ABES.

Von SPERLING, M. (2005). Introdução à Qualidade das Águas e ao Tratamento de Esgotos. Belo Horizonte: UFMG.

ZANINI, H. L., AMARAL, L. A., ZANINI, J. R., \& TAVARES, L. H. (2010). Caracterização da água da microbacia do córrego rico avaliada pelo índice de qualidade de água e estado trófico. Eng, Agríc. , 732 $-741$.

ZILLMER, T.A.; VARELLA, R.F.; ROSSETE, A.N. . (2007). Avaliação de algumas características fisico-químicas da água do rio Ribeirão Salgadinho, Nova Xavantina/MT. Holos Environment, 124. 